\title{
Development of Mathematical Functions to Predict Deflection of Radial and Bias Tractor Tires on Rigid Surface
}

\author{
Fırat Kömekçii ${ }^{1, a}$, Adnan Değirmencioğlu',b,* \\ ${ }^{1}$ Department of Agricultural Machinery and Technologies Engineering, Ege University, Faculty of Agriculture, 35100 İzmir, Turkey \\ *Corresponding author
}

\section{A R T I C L E I N F O A B S T R A C T}

Research Article

The objective of this study was to develop mathematical functions to predict deflection for radial and bias tires. In order to develop the models, the data were obtained from the tire manufacturing companies and organized in Excel first and then transferred to Minitab $®$ for stepwise regression analysis. The variables considered in the study were inflation pressure, load and tire width and

Received : 08/06/2021

Accepted : 27/07/2021 overall diameter. Tire width (w) and overall diameter (d) was considered in a multiplication form. The tire deflection models in two different form (linear and non-linear) were developed for both, radial and bias tires. The model selection was achieved by three different criteria and \% differences between the measured and predicted data. Based on the results of applying model selection criteria, the models for radial and bias tire in non-linear form were found to be adequate for predicting the

Keywords:

Mathematical modelling tire deflection. The results from the stepwise analysis indicated that the load on tire was the predominant variable in the models and made the highest contribution to the prediction functions. Model selection Tire stiffness Non-linear models Tire size The developed models were verified against to published literature data and found a good agreement.

a firat.komekci@ege.edu.tr

\section{Introduction}

Back in the 1950s, the radial tire named Cinturato (means belted) by Pirelli (Mention of trademark or company name does not imply the endorsement of the company and its products by the authors and their institution) was invented and as a result of this invention, the studies concerning the behavior of radial and bias tires under load and their tractive characteristics were initiated. These studies were conducted mostly in comparison manner. Tire deflection is one of the typical examples of tire behavior under load and that is a result of tire construction, tire related variables, inflation pressure and load. Depending upon the surface, the deformation either occurs totally on tire on rigid surface while the deformation is shared by tire and soil if the tire interacts with soil. The reason for finding tire deflection is that the tire contact length and width and then the contact area can be calculated (Wong, 1978; Bekker, 1985; Upadhyaya and Wulfson, 1990).

Komandi (1976) developed a function for the prediction of deflection as in the following:

$$
\Delta \mathrm{R}=\mathrm{C}_{1} \frac{\mathrm{Q}^{0.85}}{\mathrm{~B}^{0.7} \mathrm{D}^{0.43} \mathrm{P}^{0.6}} \mathrm{~K}(\mathrm{~cm})
$$

where $C_{1}$ is 1.15 for conventional, 1.5 for radial tires.

$$
\begin{aligned}
& \mathrm{K}=15 \times 10^{-3} \times \mathrm{B}+0.42 \\
& \text { Q: wheel load }(\mathrm{kp}) \\
& \mathrm{B}: \text { width of tire }(\mathrm{cm}) \\
& \text { D: diameter of tire }(\mathrm{cm}) \\
& \text { P: inflation pressure }\left(\mathrm{kp} \mathrm{cm}^{-2}\right)
\end{aligned}
$$

Komandi (1976) then developed contact area model and used ten different conventional tires. Experiments conducted on concrete pavement suggested the following empirical relationship:

$$
\begin{aligned}
& L^{\prime}=1.7 \sqrt{(D-\Delta r) \Delta r} \\
& F=\left(L^{\prime}-b\right) b+\frac{\pi}{4} b^{2}
\end{aligned}
$$

Where $L^{\prime}$ is the length of contact area, a function of tire diameter (D) and deflection $(\Delta r)$, and $\mathrm{b}$ is the width of the contact area, $\mathrm{F}$ is the contact area. But the models developed were only valid for a tire size range from 9-24 
to $15-30$ and at inflation pressures varying between 0.4 to $1.6 \mathrm{kp} \mathrm{cm}^{-2}$ (39.2 to $157.0 \mathrm{kPa}$ ).

Rafiee et al. (2014) conducted a study to develop deflection model for bias tires and considered section width (b) and overall unloaded diameter (d), inflation pressure $(\mathrm{P})$, vertical load $(\mathrm{W})$ and rotational speed $(\mathrm{N})$. For this purpose, deflection of three bias-ply tires with different section width and overall unloaded diameter were measured at three levels of inflation pressure, four levels of vertical load and six levels of rotational speed. They developed a model in linear form of the variables considered.

Painter (1981) presented a simple geometrical theory for pneumatic tire deflection under load on a smooth, rigid, plane surface. The model consisted of dimensionless terms created by using the principles of dimensional analysis. He verified his model with limited number of tires.

Upadhyaya and Wulfson (1990) developed functions to predict contact length, width and then for calculating the contact area of a tire. For the contact length and width of the tire, they developed the equations given below.

$$
\begin{aligned}
& \frac{l_{c}}{d}=2 \sqrt{\frac{\delta_{z}}{d}} \\
& \frac{l_{w}}{2 R_{2}}=2 \xi \sqrt{\frac{\delta_{z}}{2 R_{2}}} \\
& A_{c}=\frac{l_{c} l_{w}}{4}[\pi-2 \eta]
\end{aligned}
$$

where,

$\delta_{z}$ : deflection

$1_{c}$ : contact length

d: overall diameter

$1_{\mathrm{w}}$ : contact width

$\mathrm{R}_{2}$ : tread radius

$\xi$ : coefficient and $\eta$ is a function of $1_{w}$

The literature review indicates that the tire deflection is a key parameter and it is an indicator of how stiff the tire is. It is used in order to find out tire behavior under load (stiffness) and for finding contact length and width and finally for calculation of contact area. The literature search revealed that the theoretical or empirical tire deflection models were created with a limited number of data and then tested. This means that there is no model that makes prediction of deflection in a wide range of tire related variables (width and diameter), inflation pressure and load in the literature. Hence, a study was conducted and the objective of this study was to develop mathematical functions to predict deflection for radial and bias tires.

\section{Materials and Method}

The data to develop mathematical functions to predict tire deflection for both, radial and bias tires were obtained from the published catalogues of two tire manufacturing companies. The number of the data and the manufacturers to develop mathematical functions for tire deflection are tabulated in Table 1. A schematic view of a tire cross section is depicted in Figure 1.
Table 1. Data used to develop prediction functions for deflection for radial and bias tires from different companies

\begin{tabular}{l|ccc}
\hline \multicolumn{1}{c|}{ Model } & Company & $\begin{array}{c}\text { Number of } \\
\text { data points }\end{array}$ & Total \\
\hline $\begin{array}{l}\text { Deflection for } \\
\text { radial tires }\end{array}$ & A & 264 & 456 \\
\hline $\begin{array}{l}\text { Deflection for } \\
\text { bias tires }\end{array}$ & A & 192 & 264 \\
\hline
\end{tabular}

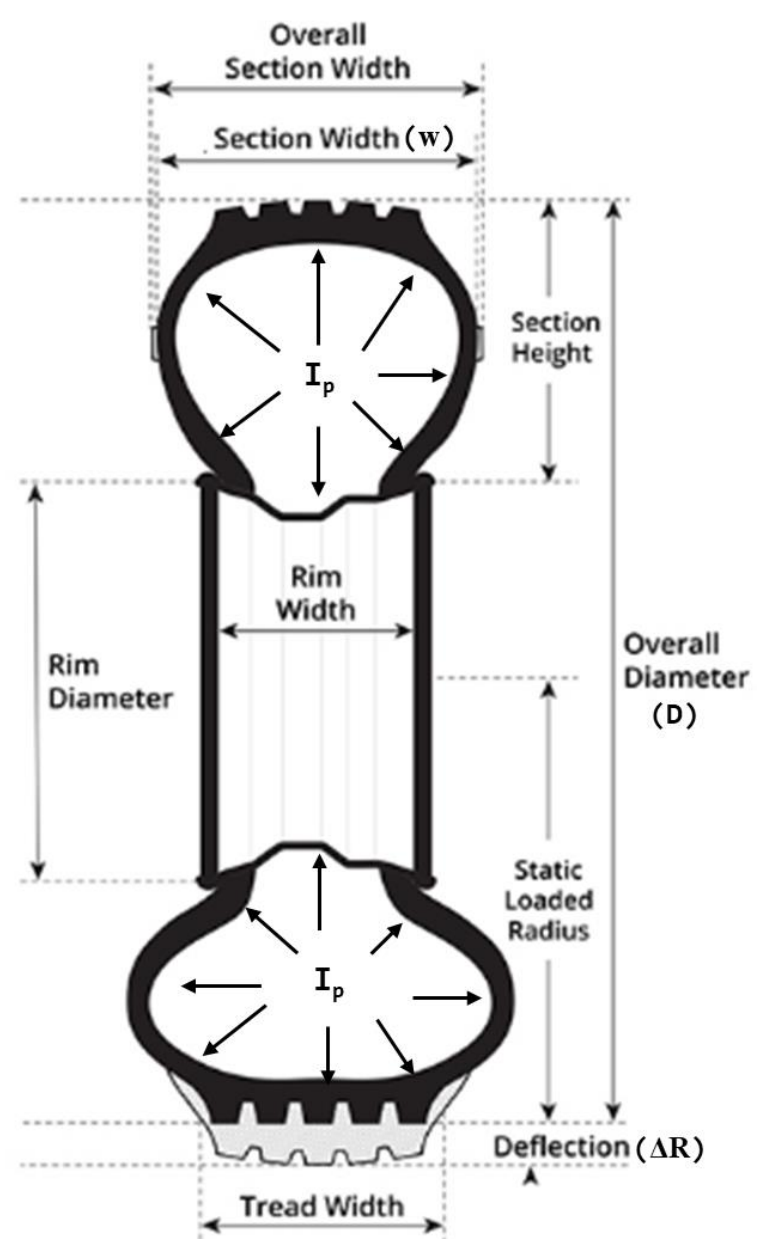

Figure 1. A schematic view of a tire cross section

The deflection function theoretically considered as in the following:

$\Delta \mathrm{R}=f\left(\mathrm{I}_{\mathrm{p}}, \mathrm{L}, \mathrm{wD}\right)$

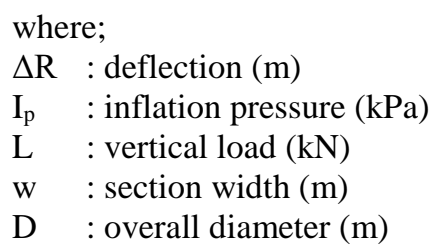

As understood from the theoretical deflection model, width of the tire and overall diameter was considered in a multiplication form that refers to a tire size (TS) as it was used by Diserens et al. (2011) for the development of contact area models for agricultural tires. 
In the catalogues, the above mention variables were given along with the static loaded radius. From the catalogue values, tire deflection $(\Delta \mathrm{R})$ on a rigid surface was calculated to be overall diameter/ 2 minus the static loaded radius.

A significant number of data were obtained from the catalogues and organized in Excel first and then transferred to Minitab ${ }^{\circledR}$ V19 for stepwise analysis at a probability level of $\alpha=0.05$.

Even though many different model types with different with or without transformations to the variables were developed but the predictions of such models were not acceptable level in terms of model selection criteria that described below. Hence, only two different models for deflection (Table 2) for both, radial and bias tires were considered in this paper.

The model selection criteria are the coefficient of correlation ( $r$ ) and the lower the $\mathrm{E}_{\mathrm{RMS}}$ and $\chi^{2}$ as used many mathematical modelling studies (Phitakwinai et al. 2019; Kouhila et al. 2020; Özdemir and Değirmencioğlu, 2020; Alibaş et al. 2021) Additionally, \% difference values were also used for the comparison purposes.

$$
\begin{aligned}
& \mathrm{E}_{\mathrm{RMS}}=\left[\frac{1}{\mathrm{~N}} \sum_{\mathrm{i}=1}^{\mathrm{N}}\left(\mathrm{Y}_{\text {pred., }}-\mathrm{Y}_{\text {mea.,i }}\right)^{2}\right]^{1 / 2} \\
& \chi 2=\frac{\sum_{i=1}^{N}\left(Y_{\text {pred.i }, i}-Y_{\text {mea. }, i}\right)^{2}}{N-n_{1}} \\
& \text { Difference }(\%)=\frac{\mathrm{Y}_{\text {pred_- }} \mathrm{Y}_{\text {mea }}}{\mathrm{Y}_{\text {mea }}} 100
\end{aligned}
$$

where;

$\mathrm{E}_{\mathrm{RMS}}$ root mean square error

$\chi^{2} \quad$ : khi square

$\mathrm{Y}_{\text {pre. }}$ : predicted deflection

$Y_{\text {mea. }}$ : measured deflection

$\mathrm{N}$ : number of measurements

$\mathrm{n} \quad$ : number of model constants

The higher the coefficient of correlation (r) and the lower the $\mathrm{E}_{\mathrm{RMS}}$ and $\chi^{2}$ are, the better the models make predictions.

Table 2. Theoretical model forms considered for the prediction of deflection for radial and bias tires

\begin{tabular}{l|c}
\hline Model description & Theoretical form of the model \\
\hline Linear model & $\Delta \mathrm{R}=\mathrm{b}_{1}+\mathrm{b}_{2} \mathrm{I}_{\mathrm{p}}+\mathrm{b}_{3} \mathrm{~L}+\mathrm{b}_{4} \mathrm{wD}$ \\
Power model & $\Delta \mathrm{R}=\mathrm{b}_{1} \mathrm{I}_{\mathrm{p}}{ }^{\mathrm{b} 2} \mathrm{~L}^{\mathrm{b} 3} \mathrm{wD}^{\mathrm{b} 4}$ \\
\hline \multicolumn{2}{c}{$\mathrm{b}_{1}, \mathrm{~b}_{2} \ldots \ldots \mathrm{b}_{4}$ are model constants } \\
\hline
\end{tabular}

\section{Results and Discussion}

The following deflection models were developed for radial tires:

$$
\begin{aligned}
& \Delta \mathrm{R}_{\mathrm{r}}=0.0544-3.367 \times 10^{-5} \mathrm{Ip}+0.000291 \mathrm{~L}+0.0304(\mathrm{wD}) \quad(11) \\
& \quad\left(\mathrm{R}^{2}=0.729\right)
\end{aligned}
$$$$
\Delta \mathrm{R}_{\mathrm{r}}=0.0169 \mathrm{Ip}^{-0.242} \mathrm{~L}^{0.368}(\mathrm{wD})^{0.129}\left(\mathrm{R}^{2}=0.807\right)
$$

As seen from the models, inflation pressure is inversely related with tire deflection while increase in load and wD results in an increase in tire deflection.

The models developed are valid under the following conditions for deflection for radial tires:

$$
\begin{aligned}
& 117.2 \leq \mathrm{I}_{\mathrm{p}} \leq 579.1 \mathrm{kPa} \\
& 0.228 \leq \mathrm{W} \leq 1.028 \mathrm{~m} \\
& 0.86 \leq \mathrm{D} \leq 2.33 \mathrm{~m} \\
& 11.54 \leq \mathrm{L} \leq 137.2 \mathrm{kN}
\end{aligned}
$$

These two models were subjected to model selection criteria in order to select the one and the results from the comparison of two radial tire deflection models based on the criteria are tabulated in Table 3.

In terms of three criteria along with \% difference range, the power model seems to be the one to be selected for predicting the tire deflection for radial tires. The distribution of $\%$ difference for four different range for radial tires are tabulated in Table 4 . As seen from the table, the $\%$ differences for power form model accumulated within the -10 and $+10 \%$ range $(66 \%)$. The overall range in the power form varies between -26.74 and $+27.67 \%$. This range is considered to be acceptable since only four variables from the catalogues were used in order to create simple models such that the variables can be readily obtained. The changes in number of plies and carcass form of the tires may affect the deflection but these were not considered in modelling studies.

The models given in equation 11 and 12 were obtained by regressing the variables using stepwise procedure at a probability level of $95 \%$. The results from the stepwise analysis for the power model are tabulated in table 5 since this model for radial tires was selected.

As seen from the table, the highest contribution to the model is made by load. Inflation pressure and $\mathrm{wD}$ were also included in the model at a probability level $95 \%$.

The data used to create the model in power form were correlated with the predictions and the comparison of measured and predicted deflections is shown in Figure 2. As seen from the figure, the data accumulated on or around the diagonal line that represents perfect fit. The correlation coefficient (r) between the two was found to be 0.898 .

The data obtained from the tire manufacturers catalogues for bias tires were also analyzed as in the same way used to create models for radial tires and the following models were developed for bias tires:

$$
\begin{aligned}
& \begin{array}{l}
\Delta \mathrm{R}_{\mathrm{b}}=0.0172-6.06 \times 10^{-5} \mathrm{Ip}+0.00047 \mathrm{~L}+0.0606(\mathrm{wD}) \\
\quad\left(\mathrm{R}^{2}=0.866\right)
\end{array} \\
& \Delta \mathrm{R}_{\mathrm{b}}=0.114 \mathrm{Ip}^{-0.234} \mathrm{~L}^{0.252}(\mathrm{wD})^{0.1291}\left(\mathrm{R}^{2}=0.907\right)
\end{aligned}
$$

As understood from model equations given above, increasing load and $\mathrm{wD}$ resulted in an increase in tire deflection while inflation pressure caused a reduction. The sign for multiplication of width and overall diameter is positive and this means that the increase width and diameter interaction increases the deflection. This is controversial with Equation 1 as developed for bias tires by Komandi (1976) since tire diameter was inversely related with tire deflection. 
Table 3. Results from the model comparisons to predict the deflection $(\Delta \mathrm{Rr})$ for radial tires based on three criteria and

\begin{tabular}{l|cccc}
\multicolumn{1}{c|}{ \% difference } & $\mathrm{r}$ & $\mathrm{E}_{\mathrm{RMS}}$ & $\chi^{2}$ & $\%$ difference \\
\hline Model description & 0.85 & 0.0104 & 0.00011 & -28.9 and +35.71 \\
Linear model & 0.898 & 0.0038 & $8.8610^{-5}$ & -26.74 and +27.67 \\
\hline
\end{tabular}

Table 4. Distribution of $\%$ difference for the tire deflection comparisons between the measured and predicted values for radial tires

\begin{tabular}{|c|c|c|c|c|c|}
\hline Model & \multicolumn{5}{|c|}{ Ranges for $\%$ difference* } \\
\hline Linear & $\begin{array}{c}-28.59 \text { and }-10 \\
16 \%(73)\end{array}$ & $\begin{array}{c}-10 \text { and } 0 \\
26.5 \%(121) \\
62\end{array}$ & $\begin{array}{l}0 \text { and }+10 \\
36.0 \%(164) \\
5)\end{array}$ & $\begin{array}{c}+10 \text { and }+35.7 \\
21.5 \%(98)\end{array}$ & $\begin{array}{c}\text { Total } \\
100 \%(456)\end{array}$ \\
\hline Power & $\begin{array}{c}-26.74 \text { and }-10 \\
16.9 \%(77)\end{array}$ & $\begin{array}{l}-10 \text { and } 0 \\
29.3(134)\end{array}$ & $\begin{array}{l}0 \text { and }+10 \\
36.7 \%(167)\end{array}$ & $\begin{array}{c}+10 \text { and }+27.67 \\
17.1 \%(78)\end{array}$ & $\begin{array}{c}\text { Total } \\
100 \%(456)\end{array}$ \\
\hline
\end{tabular}

*The numbers in parenthesis are the number of data points.

Table 5. The results from the stepwise regression analysis (Equa.12) for the deflection for radial tires

\begin{tabular}{c|cc}
\hline Variable & \% contribution & $\mathrm{P}$ value \\
\hline Inflation pressure $(\mathrm{Ip} ; \mathrm{kPa})$ & 0.56 & $<0.001$ \\
Vertical load $(\mathrm{L} ; \mathrm{kN})$ & 79.82 & $<0.001$ \\
Section width x overall diameter $\left(\mathrm{wD} ; \mathrm{m}^{2}\right)$ & 0.37 & $<0.001$ \\
Model $\mathrm{R}^{2}$ & 0.8075 & \\
\hline
\end{tabular}

Table 6. Results from the model comparisons to predict the deflection $(\Delta \mathrm{Rb})$ for bias based on three criteria and $\%$ difference

\begin{tabular}{l|cccc}
\hline Model description & $\mathrm{r}$ & $\mathrm{E}_{\mathrm{RMS}}$ & $\chi^{2}$ & $\%$ difference \\
\hline Linear model & 0.930 & 0.0069 & $4.8810^{-5}$ & -22.71 and +34.82 \\
Power model & 0.952 & 0.0066 & $4.4910^{-5}$ & -23.24 and +24.94 \\
\hline
\end{tabular}

Table 7. Distribution of $\%$ difference for the tire deflection comparisons between the measured and predicted values for bias tires

\begin{tabular}{|c|c|c|c|c|c|}
\hline Model & \multicolumn{5}{|c|}{ Ranges for $\%$ difference* } \\
\hline \multirow[t]{2}{*}{ Linear } & $\begin{array}{c}-22.71 \text { and }-10 \\
14.8 \%(39)\end{array}$ & $\begin{array}{l}-10 \text { and } 0 \\
31.4 \%(83)\end{array}$ & $\begin{array}{c}0 \text { and }+10 \\
32.6 \%(86)\end{array}$ & $\begin{array}{c}+10 \text { and }+34.82 \\
21.2 \%(56)\end{array}$ & $\begin{array}{c}\text { Total } \\
100 \%(264)\end{array}$ \\
\hline & \multicolumn{4}{|c|}{$64 \%(169)$} & \\
\hline \multirow[t]{2}{*}{ Power } & $\begin{array}{c}-23.24 \text { and }-10 \\
16 \%(42)\end{array}$ & $\begin{array}{l}-10 \text { and } 0 \\
32.2(85)\end{array}$ & $\begin{array}{c}0 \text { and }+10 \\
34.4 \%(91)\end{array}$ & $\begin{array}{c}+10 \text { and }+24.94 \\
17.4 \%(46)\end{array}$ & $\begin{array}{c}\text { Total } \\
100 \%(264)\end{array}$ \\
\hline & \multicolumn{4}{|c|}{$66.6 \%(176)$} & \\
\hline
\end{tabular}

*The numbers in parenthesis are the number of data points.

On the other hand, one of the bias tire deflection models by Rafiee et al. (2014) was in the form as in the following:

$$
\Delta \mathrm{r}=17.795+0.00002(\mathrm{wD})-0.3667 \mathrm{I}_{\mathrm{P}}+0.0356 \mathrm{~L}-0.0050 \mathrm{~N}
$$

As seen from the model, the sign for multiplication of width and overall diameter is positive just like in deflection models developed in this study. Actually, the multiplication of $\mathrm{wD}$ is a kind of indicator of theoretical contact area since McKyes (1985) suggested a contact area model on rigid surface in the following form:

$$
A_{c}=\frac{w D}{4}
$$

For the model selection, the results from the model selection criteria along with $\%$ difference values were calculated and tabulated in Table 6.
Considering the model selection criteria and \% difference values, it could be stated that power model is the model that can be selected for the deflection predictions for bias tires.

Differences $(\%)$ were divided into four groups and the results are given in Table 7 . As seen from the table, most of the data accumulate within -10 and $+10 \%$ range.

The results from regression analysis for power model are given in Table 8 . As it was the case for radial tires, load on tire was found to be the predominant variable as a result of stepwise regression analysis. Inflation pressure and section width $\mathrm{x}$ overall diameter was also brought into the model at a probability level of $95 \%$.

The comparison of measured and predicted deflection for bias tires is depicted in Figure 3. As seen from the figure, the data accumulate on or around the diagonal line with a correlation coefficient of 0.952 . 
Table 8. The results from the stepwise regression analysis (Equa. 14) for the deflection for bias tires

\begin{tabular}{c|cc}
\hline Variable & \% contribution & P value \\
\hline Inflation pressure $(\mathrm{Ip} ; \mathrm{kPa})$ & 2.30 & $<0.001$ \\
Load $(\mathrm{L} ; \mathrm{kN})$ & 86.61 & $<0.001$ \\
Section width x overall diameter $\left(\mathrm{wD}-\mathrm{m}^{2}\right)$ & 1.83 & $<0.001$ \\
Model R & 0.9074 & \\
\hline
\end{tabular}

Table 9. Load-deflection constants and selected stiffness values and calculated loads on tire

\begin{tabular}{c|cccc}
\hline Inflation pressure $(\mathrm{kPa})$ & $\mathrm{a}$ & $2 \mathrm{~b}$ & $\mathrm{k}(\mathrm{N} / \mathrm{m})$ & Load $(\mathrm{N})$ \\
\hline 41 & 55628 & 1066160 & 140000 & 11079.1 \\
83 & 87092 & 1506772 & 200000 & 14986.7 \\
124 & 101815 & 3176060 & 350000 & 27349.8 \\
124 & 101815 & 3176060 & 400000 & 37554.1 \\
\hline
\end{tabular}

Table 10. Comparison of deflection values as measured by Taylor et al (2000) and predicted ones from the developed model for radial tires

\begin{tabular}{c|cccc}
\hline Inflation pressure $(\mathrm{kPa})$ & Load $(\mathrm{N})$ & $\begin{array}{c}\text { Deflection } \\
\text { by Taylor et al }\end{array}$ & Predicted & $\%$ Difference \\
\hline 41 & 11079.1 & 0.079 & 0.070 & 12.885 \\
83 & 14986.7 & 0.075 & 0.066 & 13.445 \\
124 & 27349.8 & 0.078 & 0.075 & 4.482 \\
124 & 37554.1 & 0.094 & 0.084 & 11.710 \\
\hline
\end{tabular}

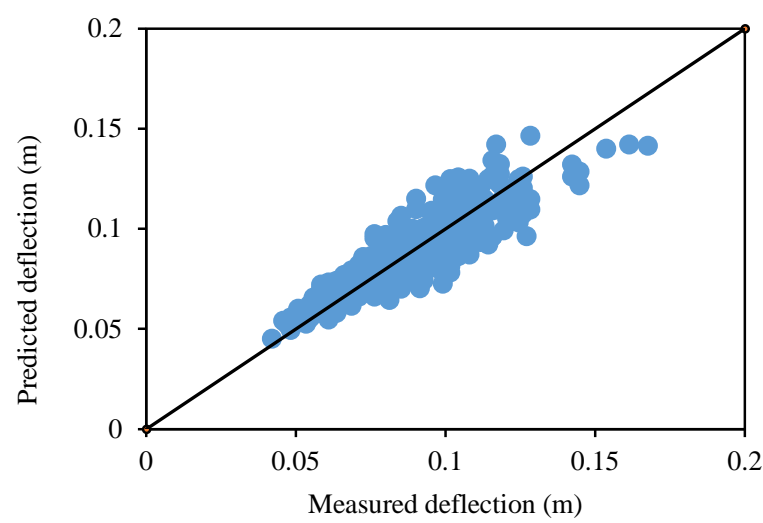

Figure 2. Comparison of the measured and predicted (Equa. 12) deflection for radial tires

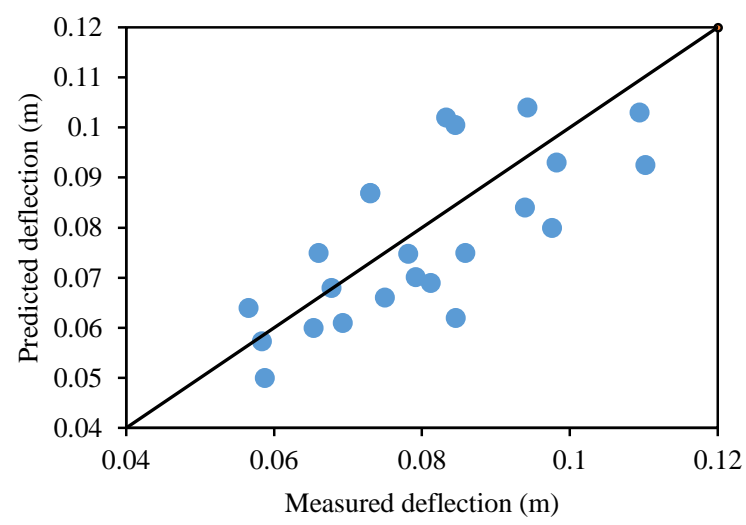

Figure 4. Comparison of predicted (Equa. 12) and published deflection data for radial tires

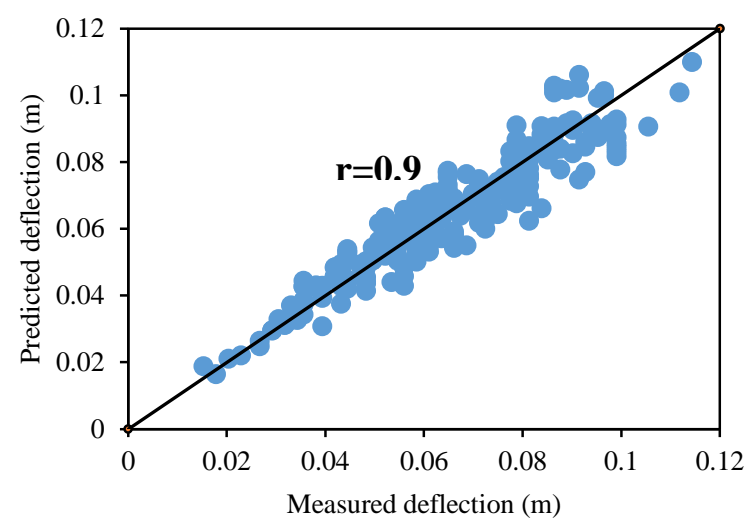

Figure 3. Comparison of the measured and predicted (Equa.14) deflection for bias tires

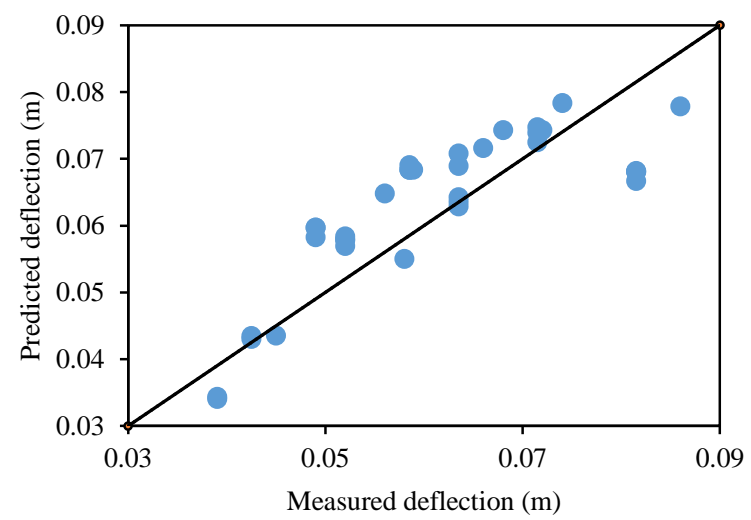

Figure 5. Comparison of predicted (Equa. 14) and published deflection data for bias tires 
Verification of the Developed Models Against to Published Data

The deflection model developed for radial tires was verified against to published literature data. The comparison results are depicted in Figure 4. For the comparison purposes, the data obtained from different studies conducted by Wulfsohn and Upadhyaya (1992), Brassart and Wright (1993), Taylor et al. (2000), Ragheb et al. (2013), Wang et al. (2014), Anonymous (2018) and Guo and Zhou (2019). The percent differences between the predicted and measured tire deflection data ranged between -27.5 and $+22.5 \%$.

As mentioned above, the data for comparison purposes for the deflection of radial tires were compiled from different sources. One of them was the study conducted by Taylor et al. (2000).

Taylor et al. (2000) measured the vertical stiffness using a 260/80R20 radial ply agricultural drive tire using five methods. These methods were load-deflection, non-rolling vertical free vibration, non-rolling equilibrium loaddeflection, rolling vertical free vibration, and rolling equilibrium load-deflection. They conducted experiments at three different inflation pressures $(41,83$, and $124 \mathrm{kPa})$. They recommended the following equation due to simplicity;

$$
\mathrm{L}=\mathrm{a} \delta+\mathrm{b} \delta^{2}
$$

where;

L: vertical load $(\mathrm{N})$

$\Delta$ : vertical deflection $(\mathrm{m})$

a: regression coefficient $\left(\mathrm{N} \mathrm{m}^{-1}\right)$

b: regression coefficient $\left(\mathrm{N} \mathrm{m}^{-2}\right)$

Vertical stiffness was determined by taking the first derivative of load with respect to deflection. This resulting stiffness increases linearly with deflection

$$
\mathrm{k}=\mathrm{a}+2 \mathrm{~b} \delta
$$

where;

$\mathrm{k}$ : vertical stiffness $\left(\mathrm{N} \mathrm{m}^{-1}\right)$

$\delta$ : vertical deflection $(\mathrm{m})$

a: regression coefficient $\left(\mathrm{N} \mathrm{m}^{-1}\right)$

b: regression coefficient $\left(\mathrm{N} \mathrm{m}^{-2}\right)$

They reported the coefficients of load-deflection coefficients as a function of inflation pressure as in the following (Table 9).

As seen from the above table, for different stiffness (k) values, deflection was calculated using equation 17 and then using equation 17 , the load on tire $(\mathrm{N})$ was found. The deflection found from Taylor et al. (2000) approach was compared with the model developed for radial tires in this study as seen in Table 10. The reason for making limited number of comparison is due to the range for load $(11.54 \leq \mathrm{L}$ $\leq 137.2 \mathrm{kN}$ ) to develop deflection function for radial tires and range for stiffness values as reported by Taylor et al (2000).

As seen from Table 10, \% differences between the Taylor et al (2000) and predicted values ranged between 4.48 and 13.44. These differences are at acceptable level. This comparison clearly shows the importance especially load and inflation pressure since the coefficients ( $\mathrm{a}$ and $2 \mathrm{~b}$ ) were found as a function of inflation pressure and then the deflection was calculated from the load.
Dwyer et al. (1974), Matthews and Talamo (1965) and a tire company data (Anonymous, 2018) were used for comparisons. The comparison of the predicted deflection and the literature data are shown in Figure 5. The percent differences between the predicted and measured tire deflection data ranged between -18.1 and $+19 \%$. These differences are assumed to be at acceptable level.

As a final statement, it could be stated that the models developed in this study have built on widest range of variables in the literature. The variables considered for the development of the models are the ones that can be readily obtained.

\section{Conclusions}

The followings were concluded from the study conducted:

- The developed models to predict deflection in this study were in non-linear (power) form and function of inflation pressure, load and tire size $(\mathrm{TS}=$ section width $\mathrm{x}$ overall diameter).

- Increasing the load and TS increased the deflection while an increase in inflation pressure reduced the tire deflection.

- The predominant variable was the load on tire and made the highest contribution to the models (79.82 and $86.61 \%$ to radial and bias tire power model, respectively.)

- The predictions from the models were verified against to published data available in the literature and found a good agreement.

- The models developed are the ones that have the widest range of variables as considered to be the load on tire, inflation pressure and TS.

\section{References}

Alibaş İ, Yılmaz A, Günaydın S, Arkain B. 2021. Influence of drying methods on drying kinetics and color parameters. Turkish Journal of Agriculture - Food Science and Technology, 9(5): 897-908. doi: 10.24925/turjaf.v9i5.897908.4170

Anonymous. 2018. Titan - OTR Tires. Available from: https://www.titan-intl.com//media/Files/OTRDB_Vol8b.ashx [Accessed 28 April 2021]

Bekker MG. 1985. The effect of tire tread in parametric analyses of tire-soil systems. NRCC Report No. 24146, National Research Council of Canada.

Brassart FP, Wright ME. 1993. A machine to study vertical tire stiffness and damping coefficient. 1993. International OffHighway \& Powerplant Congress \& Exposition Milwaukee, Wisconsin, September 13-15, 1993.

Diserens E, De' fossez P, Duboisset A, Alaoui A. 2011. Prediction of the contact area of agricultural traction tires on firm soil. Biosystems Engineering, 110(2): 73-82. doi: 10.1016/j.biosystemseng.2011.06.008

Dwyer MI, Comely DR, Evernden DW. 1974. The field performance of some tractor tyres related to soil mechanical properties. Journal of Agricultural Engineering Research, 19: 35-50. doi: 10.1016/0021-8634(74)90005-5

Guo M., Zhou X. 2019. Tire-pavement contact stress characteristics and critical slip ratio at multiple working conditions. Hindawi Advances in Materials Science and Engineering Volume 2019, Article ID 5178516, 11 pages. doi: $10.1155 / 2019 / 5178516$ 
Komandi G. 1976. The determination of the deflection, contact area, dimensions and load carrying capacity for driven pneumatic tires operating on concrete pavement. Journal of Terramechanics, 13(1): 15-20. doi: 10.1016/00224898(76)90028-8

Kouhila M, Moussaoui H, Lamsyehe H, Tagnamas Z, Bahammou Y, Idlimam A, Lamharrar A. 2020. Drying characteristics and kinetics solar drying of Mediterranean mussel (mytilus galloprovincilis) type under forced convection. Renewable Energy, 147(1):883-844 doi: 10.1016/j.renene.2019.09.055

Matthews J, Talamo JDC. 1965. Ride comfort of tractor operators, III. Investigation of tractor dynamics by analog computer simulation. Journal of Agricultural Engineering Research, 12(1): 93-108. doi: 10.1016/0021-8634(65)900570

McKyes E. 1985. Soil Cutting and Tillage. Elsevier, Amsterdam, Netherlands, $217 \mathrm{pp}$.

Minitab®19. User Manual, Getting started with Minitab 19 for Windows, www. minitab.com, (V19; Free Trial Version).

Özdemir MH, Değirmencioğlu A. 2020. Mathematical modelling of the volumetric efficiency for fluted rolls metering different crop seeds. Turkish Journal of Agriculture - Food Science and Technology, 8(11): 2453-2459. doi: 10.24925/turjaf.v8i11.2453-2459.3755

Painter DJ. 1981. A simple deflection model for agricultural tyres. Journal of Agricultural Engineering Research, 26: 9-20. doi: 10.1016/0021-8634(81)90123-2

Phitakwinai S, Thepa S, Nilnont W. 2019. Thin-layer drying of parchment Arabica coffee by controlling temperature and relative humidity. Food Science and Nutrition. 2019(7):2921-2931. doi: 10.1002/fsn3.1144
Rafiee K, Majid R, Mohammad G, Parham F, Siamak A, Babak J. 2014. Modeling of bias-ply tire deflection based on tire dimensions, inflation pressure, vertical load and rotational speed. American-Eurasian Journal of Agricultural and Environmental Science, 14(8): 763-770. doi: 10.5829/idosi.aejaes.2014.14.08.12395

Ragheb H, El-Gindy M, Kishawy H A. 2013. Multi-wheeled combat vehicle tire modeling on rigid and soft terrain. Proceedings of the 15th ASAT-15 Conference, 28-30 May, 2013

Taylor RK, Bashford LL, Schrock MD. 2000. Methods for measuring vertical tire stiffness. Transactions of the ASAE, 43(6): 1415-1419. doi: 10.13031/2013.3039

Upadhyaya SK, Wulfsohn D. 1990. Relationship between tire deflection characteristics and 2-D tire contact area. Transactions of the ASAE, 33(1): 25-30. doi: $10.13031 / 2013.31288$

Wang H, Imad L, Al-Qadi, Stanciulescu I. 2014. Effect of surface friction on tire-pavement contact stresses during vehicle maneuvering. Journal of Engineering Mechanics, 140(4). doi: 10.1061/(ASCE)EM.1943-7889.0000691

Wong JY. 1978. Theory of Ground Vehicles. John Wiley and Sons, New York, USA.

Wulfsohn D, Upadhyaya SK. 1992. Determination of dynamic three-dimensional soil-tyre contact profile. Journal of Terramechanics. 29(4/5): 433-464. doi: 10.1016/00224898(92)90046-M 